\title{
Effects of Pelvic Tilt Training using Inclinometer on Joint Position Sense and Postural Alignment in Patients with Chronic Stroke
}

\author{
Ja-Shin Gu', Sung-Jin Choi ${ }^{2}$ Ho-Suk Choi ${ }^{2}$, Won-Seob Shin ${ }^{3}$ \\ 'Department of Physical Therapy, Graduate School of Health and Medicine, Daejeon University; ${ }^{2}$ Department of Physical Therapy, Graduate School \\ of Daejeon University; ${ }^{3}$ Department of Physical Therapy, College of Health and Medical Science, Daejeon University, Daejeon, Korea
}

Purpose: The aim of this study was to determine the effectiveness of pelvic tilt training using an inclinometer on joint position sense and postural alignment in individuals with stroke.

Methods: Thirty-one subjects with chronic stroke were divided into two groups: the experimental group (16 subjects) and the control group (15 subjects). Subjects in both groups received neuro-developmental therapy five times per week. In addition, the patients in the experimental group also received pelvic tilt training using an inclinometer for 30 minutes, 3 times a week for 4 weeks. Maximal range of anterior, posterior pelvic tilt and joint position sense were used to evaluate pelvic tilt motion. Image analysis was performed for evaluation of postural alignment on in standing position.

Results: Significant difference in limprovement of pre- and post-intervention of joint position sense was observed showed significant difference $(p<0.05)$ in all groups. Experimental groups showed sSignificant differences in maximal range of posterior pelvic tilt in on the paretic side were observed in the experimental groups compared to with the control group $(p<0.05)$.

Conclusion: These findings suggest that pelvic tilt training using an inclinometer may help to improve range of pelvic tilt and joint position sense of stroke patients.

Keywords: Pelvic tilt, Joint position sense, Stroke

\section{서 론}

뇌졸중 환자는 일차적으로 신경학적 문제로 인한 근력, 긴장도 및 감 각의 변화가 나타나고, 이차적으로는 근골격계적인 자세 정렬의 변 형과 연부조직 및 근육 길이 변화, 통증 발생 등의 문제들이 나타난 다. '뇌졸중 환자에게 고유수용성감각의 손상은 36-54\% 정도이며, 이 로 인하여 운동기능 회복의 지연 및 잘못된 자세 정렬과 같은 문제가 발생한다. 2,3 고유수용성감각은 신체 분절의 위치를 인식하고, 공간에 서 신체의 움직임을 조절하기 위해 사용된다. ${ }^{4}$ 이러한 고유수용성감 각은 신체 각 분절의 위치를 지각하는 위치감각과 움직임을 지각하 는 운동감각으로 구분되고 특히, 관절의 위치감각은 자세 조절에 필 수적인 기능적 안정성을 유지하는데 중요한 역할을 한다. ${ }^{5.6}$ 그러나 질환으로 인하여 자세 조절에 어려움이 있는 환자들은 비정상적인 감각정보로 인하여 일상생활동작에 장애를 갖게 되고, 이를 치료하

Received Jan 13, 2016 Revised Feb 11, 2016

Accepted Feb 22, 2016

Corresponding author Won-Seob Shin

E-mail shinws@dju.kr
는데 어려움이 있다. 이러한 고유수용성감각은 나이에 의한 노화나 질병 등에 의해 손상될 수 있으나, 비교적 가벼운 저강도의 운동에 의 해 기능이 향상될 수 있다.9 감각기능이 손상된 뇌졸중 환자에게 자 세 조절이나 기능적 움직임의 향상을 위해서는 고유수용성감각, 시 각 및 전정 감각 등을 통합하는 과정이 필요하다. ${ }^{10}$ 또한, 균형이나 보 행 증진을 위해서는 우선적으로 하지의 정상적인 정렬이 필요하고, 자세 조절을 위한 골반의 훈련이 뇌졸중 환자의 재활에 있어 중요한 과제이다."1

골반은 안정 시에는 몸통을 직립 위치를 유지할 수 있도록 지지하 는 역할을 하고, 불안정 시에는 흐트러진 신체의 균형을 회복하는데 중요한 역할을 한다. ${ }^{12}$ 골반은 위치적으로는 척추와 하지를 연결하며, 척추로부터 하지에 체중을 지지하고, 기능적인 체간 운동의 범위를 증가시키는데 필수적이다. ${ }^{13}$ 골반의 움직임 중 시상면에서 발생하는 전방, 후방 경사의 비대칭은 뇌졸중 환자에게 일반적으로 나타나는 
문제이고 이것은 하지의 내회전 또는 외회전에 영향을 준다. ${ }^{14}$ 비대칭 적인 골반의 문제는 하지 근위부와 체간을 불안정하게 만들어 정상 적인 보행을 어렵게 하고 체간 회전, 체간과 사지의 분리운동, 체중 이 동 시 골반의 전후방 움직임을 비정상적으로 만든다. ${ }^{15}$ 골반에서 전 방, 후방 경사의 정렬이 역학적으로 변화된 자세에서는 몸통의 근육 뿐만 아니라 다리에 영향을 주어 자세 안정성과 기능적으로 동적 균 형과 보행에 부정적인 영향을 미친다. ${ }^{16}$ 골반의 전방 및 후방 경사의 움직임은 척추에 영향을 주고 체간의 자세를 조절하는 역할을 하므 로 뇌졸중 환자에게 기능적 훈련을 적용하는데 있어 골반을 조절하 는 훈련이 필요하다.1718

골반의 경사운동은 앉은 자세와 선 자세에서 시행할 수 있으며, 자 세에 따라 골반운동에 관여하는 복부근육 및 체간근육, 자세 조절에 이용되는 감각정보, 생역학적인 부하에 차이가 발생한다. ${ }^{1921}$ 편마비 환자에서의 골반을 전방 및 후방으로 경사시키는 분리된 골반조절 운동은 환측 하지의 인식력을 좋게 하고, 골반 정렬의 대칭성을 증가 시킨다고 하였다.22,23 편마비 환자의 치료적 중재에 있어서 골반경사 운동은 비대칭적인 골반에 영향을 주어 체간의 안정성을 높여주고, 체간의 회전, 체간과 사지의 분리운동, 체중이동 시 골반의 전후방 운 동, 그리고 균형 등을 개선하여 보행능력을 향상시킨다는 보고가 있 다. ${ }^{24}$ 골반의 동작을 이용한 체간조절 훈련이 고관절 굴곡근과 외전 근의 근 활동을 증가시켜 하지의 안정성을 증가시킨다고 하였다. ${ }^{25}$

뇌졸중 환자의 자세 조절 능력을 향상시키기 위해 신체의 안정성 을 향상시키거나, 자세를 분석하는 연구, 생체역학적 요소를 분석하 는 연구, 체성감각이나 고유수용성감각에 대한 연구들이 지속적으 로 진행되고 있다. ${ }^{26}$ 내재적 피드백이 흔히 손상되는 뇌졸중 환자에 게 외재적 피드백은 운동 학습에 있어 중요하게 사용될 수 있다. ${ }^{27}$ 자 세 조절이 어려운 뇌졸중 환자에게 적용하는 훈련 방법으로 움직임 을 보는 것과 같은 시각적 피드백, 손을 이용한 촉각적 피드백, 접착 테이프와 피부 장력을 이용한 운동감각 피드백, 청각적 피드백 그리 고 압력 피드백과 같은 움직임을 모니터링하는 장비의 사용 등 다양 한 방법들이 있다. ${ }^{28}$ 이러한 피드백을 이용한 훈련은 고유수용성감각 과 움직임에 대한 정보를 정확하고 빠르게 제공하므로 뇌졸중 환자 에게 치료적 중재 방법으로 적합하고, 집중력 향상과 고유수용성감 각 기능을 보완함으로써 운동학습을 촉진시키고 움직임 수행 능력 을 향상시키는데 도움이 된다.

선행 연구에서 건강한 사람을 대상으로 운동 학습에 있어 피드백 훈련의 중요성을 강조하고 있고, 뇌졸중 환자의 재활 과정에서 운동 학습을 증진하기 위한 피드백 훈련에 관한 연구가 더욱 필요하다고 하였다. ${ }^{29}$ 또한 지금까지 뇌졸중 환자에게 관절위치감각과 자세 정렬 을 증진하기 위해 시각적피드백을 이용한 골반경사훈련에 관한 연구 들이 있지만, 서있는 자세에서 시각에만 의존하지 않고 경사계를 이
용하여 고유수용성감각을 자극하여 골반경사 훈련을 실시한 연구 는 없었다. 따라서 본 연구는 만성 뇌졸중 환자를 대상으로 경사계 (inclinometer)를 이용한 골반경사훈련을 실시한 이후에 관절위치감 각과 자세 정렬에 미치는 효과를 알아보고자 하였다.

\section{연구방법}

\section{1. 연구대상자}

본 연구의 대상자는 대전광역시 소재 $\mathrm{W}$ 요양병원에서 뇌졸중으로 편 마비 진단을 받은 후 6 개월 이상 경과된 환자를 대상으로 하였다. 실 험 전 모든 대상자는 본 연구의 내용을 충분히 이해하고 연구 동의서 를 작성하였고, 대상자의 성별, 손상부위, 나이, 체중, 신장, 유병기간 은 대상자의 의무기록을 통해 조사하였다. 연구대상자의 선정 기준 은 일어서기 동작을 독립적으로 수행 할 수 있는 자, 치료사의 지시사 항을 이해하고 한국판 간이 정신 상태 검사 결과(Mini Mental State Examination-Korean, MMSE-K)가 24점 이상인 자, 청각에 문제가 없 는 자, 현훈(vertigo) 및 전정기능이상(vestibular dysfunction)이 없는 자, 정형외과적 질환이나 심호흡계 질환이 없는 자로 하였다.

\section{2. 중재방법}

본 연구에 참여한 대상자는 총 31 명으로 경사계를 이용한 골반경사 훈련을 실시한 실험군 16 명, 대조군 15 명으로 각각 무작위 배정하였 다. 모든 대상자는 치료사의 지시에 따라 사지의 근력운동, 신장운동 그리고 자세 조절을 위한 신경발달치료(neuro-developmental therapy) 를 1 시간 동안, 주 5 회, 4 주간 실시하였다. 추가적으로 실험군은 경사 계를 이용한 골반경사훈련을 30 분간, 주 3 회, 4 주간 실시하였다.

실험군인 경사계를 이용한 골반경사훈련에서 대상자는 편하게 서 있는 자세에서 무릎과 체간의 굴곡, 신전의 움직임을 최소화하고, 치 료사의 지시에 따라 골반의 전방경사와 후방경사의 움직임을 스스로 재현할 수 있도록 하였다. 마비측 골반의 전상장골극과 후상장골극 을 촉진하여 경사계의 양끝 지점을 위치시키고 골반의 최대전방경사 와 최대후방경사의 각도를 측정하였다. 총 4 주의 훈련중에 초기 2 주 동안은 최대전방경사와 최대후방경사의 각각 $50 \%$ 미만의 임의의 지 점을 설정하여 치료사가 경사계를 보면서 대상자가 임의의 각도에 도 달하여 골반을 움직이도록 움직임의 정보를 구두로 알려주었다. 이 러한 과정을 3 회 반복한 이후 치료사의 피드백 없이 대상자 스스로 임의의 지점을 찾아 골반을 움직이도록 한 이후, 움직임의 결과에 대 한 오차를 제공하여 골반의 움직임을 수정하도록 하였다. 훈련 말기 2 주 동안은 골반의 최대전방경사와 최대후방경사의 각각 $50 \%$ 이상의 임의의 지점을 설정하여 위와 같은 훈련을 반복하여 실시하였다. 훈 련을 실시하는 동안 낙상 예방을 위하여 치료사가 지지 가능한 거리 
에서 실시하였고 치료 중간에 1-2분간 휴식 시간을 갖도록 하였다.

\section{3. 평가도구 및 방법}

본 연구에서는 경사계를 이용하여 마비측과 비마비측 골반의 최대 전방굴곡, 최대후방굴곡 각도를 측정하였고, 전방 및 후방 골반경사 의 관절위치감각을 측정하였다. 그리고 서있는 자세에서 경부, 슬관 절, 발목의 각도를 측정하여 자세 정렬을 측정하였다. 모두 3 회 측정 하여 그 평균값을 이용하였다.

\section{1) 골반 경사각 측정}

골반경사각의 측정은 대상자가 어깨 넓이만큼 다리를 벌리고 편하게 서있는 자세에서 측정하였다. 전상장골극(ASIS)와 후상장골극(PSIS) 을 촉진하여 경사계를 위치시키고 체간과 무릎의 신전을 유지한 상 태에서 골반을 최대한 전방경사, 후방경사 하도록 하여 시상면에서의 움직임 각도를 측정하였다. 전방경사의 경우 양의 값으로 표시하고 후방경사의 경우 음의 값으로 표시하였다. ${ }^{30}$

\section{2) 골반 경사의 관절위치감각 측정}

대상자에게 허리를 바르게 펴고 두 발을 어깨 넓이로 벌리도록 하고 두 손을 가슴위로 포개어 고정시켰다. 통증이 발생하지 않는 범위 내 에서 체간 및 슬관절의 신전을 유지하며 마비측과 비마비측 골반의 최대전방경사와 최대후방경사의 각각 $50 \%$ 되는 지점을 목표 각으로 설정하였다. 치료사는 경사계의 각도를 보면서 구두로 피드백을 주 어 대상자가 목표각으로 골반을 움직이도록 하고, 이러한 과정을 3 회 반복하여 목표각을 인식하도록 하였다. 이후 선 자세에서 대상자 스 스로 피드백 없이 전방, 후방경사의 목표각으로 골반을 움직이도록 하여 그 오차를 측정하였다.

\section{3) 자세 정렬 측정}

본 연구의 측정은 사진을 이용하여 영상분석 프로그램(Image J, NIH, USA)으로 하였다. 대상자는 편하게 서 있는 자세에서 경추7번 극돌 기와 마비측의 이주, 대전자, 비골두, 외측과, 다섯째 중수골두에 마 커를 부착하여 사진을 촬영하였다. 전방머리자세는 Nemmers드이이 제시한 이주-C7-수평각 평가방법(tragus-C7-horizontal measurement) 을 사용하여 경추 7번 극돌기와 이주에 부착된 마커의 중앙부를 연 결한 선과 수평선에서 교차하는 각도를 측정하였다. 이 평가 방법의 검사-재검사 신뢰도는 $r=0.88$ 로 매우 높은 신뢰도를 나타냈다. ${ }^{32}$ 비골 두를 중심으로 대전자와 외측과 사이의 각도를 측정하여 슬관절 각 도를 측정하였고, 외측과를 중심으로 비골두와 다섯째 중수골두 사 이의 각도를 측정하여 발목관절의 각도를 측정하였다.

\section{4. 분석 방법}

본 연구의 통계적 분석은 윈도우용 SPSS통계 프로그램 버전 18.0을 사용하였다. 연구대상자의 일반적 특성은 기술통계를 통하여 평균 과 표준편차로 나타냈고, 카이제곱검정(Chi-square test)과 독립표본 $\mathrm{t}$ 검정을 통해 군간 동질성을 확인하였다. 모든 변수의 정규성 검정을 위해 Shapiro-Wilk test를 사용하였고 그 결과 정규 분포함을 알 수 있 었다. 실험군과 대조군은 중재 전과 후를 비교하기 위하여 대응표본 $\mathrm{t}$-검정을 실시하였고, 두 군간의 변화량을 비교하기 위하여 독립표본 t-검정을 실시하였다. 모든 통계학적 유의수준은 0.05 로 설정하였다.

\section{연구결과}

\section{1. 연구대상자의 일반적 특성}

본 연구에 참여한 대상자는 총 31 명으로 실험군 16 명, 대조군 15 명의 군간 성별, 마비측, 나이, 체중, 신장, 유병기간에는 유의한 차이가 없 었으며, 연구대상자의 일반적 특성은 다음과 같다(Table 1).

\section{2. 중재 전후의 최대 골반경사 비교}

마비측 골반의 최대후방경사에서 실험군은 중재 전 평균 $-6.06 \pm 3.09^{\circ}$ 에서 중재 후 평균 $-9.47 \pm 4.15^{\circ}$ 로 유의한 차이가 있었고 $(\mathrm{p}<0.05)$, 두 군 의 중재 전후 변화량 비교에서 유의한 차이가 있었다 $(\mathrm{p}<0.05)$. 비마비 측 골반의 최대후방경사에서 실험군 대조군 모두 중재 전후에 유의 한 차이가 있었으나 $(\mathrm{p}<0.05)$, 실험군과 대조군 사이에는 유의한 차이 가 없었다(Table 2).

\section{3. 중재 전후의 관절위치감각 비교}

마비측의 전방경사 관절위치감각에서 실험군 대조군 모두 중재 전후 에 유의한 차이가 있었고 $(\mathrm{p}<0.05)$, 두 군의 중재 전후 변화량 비교에 서 유의한 차이가 있었다 $(\mathrm{p}<0.05)$. 마비측 후방경사 관절위치감각에 서 실험군 대조군 모두 중재 전후에 유의한 차이가 있었고 $(\mathrm{p}<0.05)$, 두 군의 중재 전후 변화량 비교에서 유의한 차이가 있었다 $(\mathrm{p}<0.05)$. 비마비측의 전방경사 관절위치감각에서 실험군 대조군 모두 중재 전

Table 1. General characteristics of subjects

\begin{tabular}{lccc}
\hline & $\begin{array}{c}\text { Experimental group } \\
(n=16)\end{array}$ & $\begin{array}{c}\text { Control group } \\
(n=15)\end{array}$ & $\chi^{2} / \mathrm{t}$ \\
\hline Gender (Male/Female) & $12 / 4$ & $11 / 4$ & 0.011 \\
Paretic side (Right/Left) & $10 / 6$ & $9 / 6$ & 0.020 \\
Age (year) & $63.63 \pm 9.29^{*}$ & $66.33 \pm 15.51$ & -0.594 \\
Weight (kg) & $65.58 \pm 9.83$ & $58.27 \pm 8.95$ & 1.670 \\
Height (cm) & $163.13 \pm 6.30$ & $160.60 \pm 6.00$ & 1.141 \\
Duration (month) & $12.63 \pm 5.45$ & $11.73 \pm 4.96$ & 0.475 \\
\hline
\end{tabular}

${ }^{*}$ Mean $\pm S D$. 
Table 2. Comparison of maximal range of pelvic tilt between the pre and post-test on each group (unit: degree)

\begin{tabular}{lccc}
\hline & $\begin{array}{c}\text { Experimental group } \\
(\mathrm{n}=16)\end{array}$ & $\begin{array}{c}\text { Control group } \\
(\mathrm{n}=15)\end{array}$ & $\mathrm{t}$ \\
\hline PMAT & & & \\
Pre & $8.69 \pm 7.14^{*}$ & $8.50 \pm 7.26$ & 0.072 \\
Post & $7.81 \pm 6.00$ & $7.73 \pm 6.39$ & 0.036 \\
$\mathrm{t}$ & 1.054 & 0.686 & \\
Change & $-0.88 \pm 3.32$ & $-0.77 \pm 4.33$ & -0.078 \\
PMPT & & & \\
Pre & $-6.06 \pm 3.09$ & $-8.57 \pm 5.57$ & 1.534 \\
Post & $-9.47 \pm 4.15$ & $-9.20 \pm 5.23$ & -0.159 \\
$\mathrm{t}$ & $2.885^{+}$ & 1.315 & \\
Change & $-3.41 \pm 4.72$ & $-0.63 \pm 1.87$ & $-2.174^{+}$ \\
NMAT & & & \\
Pre & $9.69 \pm 7.47$ & $9.13 \pm 5.92$ & 0.228 \\
Post & $10.81 \pm 6.77$ & $8.93 \pm 5.45$ & 0.848 \\
$\mathrm{t}$ & -1.092 & 0.292 & \\
Change & $1.13 \pm 4.12$ & $-.20 \pm 2.65$ & 1.056 \\
NMPT & & & \\
Pre & $-3.88 \pm 4.53$ & $-5.40 \pm 3.70$ & 1.022 \\
Post & $-6.50 \pm 4.35$ & $-7.17 \pm 3.58$ & 0.464 \\
$\mathrm{t}$ & $4.082^{+}$ & $2.172^{+}$ & \\
Change & $-2.63 \pm 2.57$ & $-1.77 \pm 3.15$ & -0.833 \\
\hline
\end{tabular}

${ }^{*}$ Mean $\pm S D,{ }^{\dagger} p<0.05$.

PMAT: Paretic maximal anterior tilt, PMPT: Paretic maximal posterior tilt, NMAT: Non-paretic maximal anterior tilt, NMPT: Non-paretic maximal posterior tilt.

후에 유의한 차이가 있었고 $(\mathrm{p}<0.05)$, 두 군의 중재 후 비교에서 유의 한 차이가 있었다 $(\mathrm{p}<0.05)$. 비마비측의 후방경사 관절위치감각에서 실험군 대조군 모두 중재 전후에 유의한 차이가 있었고 $(\mathrm{p}<0.05)$, 두 군의 중재 전후 변화량 비교에서 유의한 차이가 있었다 $(\mathrm{p}<0.05)(\mathrm{Ta}$ ble 3).

\section{4. 중재 전후의 자세 정렬 비교}

경추부, 슬관절, 발목의 자세 정렬에서 실험군 대조군 모두 중재 전후 에 유의한 차이가 없었다. 슬관절의 자세 정렬에서 두 군의 중재 전후 변화량 비교에서 유의한 차이가 있었다 $(\mathrm{p}<0.05)$ (Table 4).

\section{고 찰}

본 연구는 뇌졸중 환자에게 골반경사의 가동범위 및 관절위치감각 과 서있는 자세의 정렬을 증진하기 위하여 경사계를 이용한 골반경 사훈련의 효과를 알아보고자 하였다. 그 결과 경사계를 이용한 골반 경사훈련이 골반의 최대후방경사와 관절위치감각에 효과가 있는 것 으로 나타났다.

뇌졸중 환자는 고관절 신전근 약화로 체간 굴곡 및 고관절 굴곡
Table 3. Comparison of joint position sense between the pre and posttest on each group (unit: degree)

\begin{tabular}{lccc}
\hline & $\begin{array}{c}\text { Experimental group } \\
(\mathrm{n}=16)\end{array}$ & $\begin{array}{c}\text { Control group } \\
(\mathrm{n}=15)\end{array}$ & $\mathrm{t}$ \\
\hline PAJPS & & & \\
Pre & $1.66 \pm 0.89^{*}$ & $1.60 \pm 1.54$ & 0.124 \\
Post & $0.55 \pm 0.58$ & $1.13 \pm 1.55$ & -1.376 \\
$\mathrm{t}$ & $5.274^{+}$ & $2.288^{+}$ & \\
Change & $-1.11 \pm 0.84$ & $-0.47 \pm 0.79$ & $-2.189^{+}$ \\
PPJPS & & & \\
Pre & $1.48 \pm 0.81$ & $1.67 \pm 1.77$ & -0.373 \\
Post & $0.31 \pm 0.43$ & $1.18 \pm 1.83$ & -1.796 \\
$\mathrm{t}$ & $6.194^{+}$ & $2.251^{+}$ & \\
Change & $-1.17 \pm 0.76$ & $-0.48 \pm 0.83$ & $-2.413^{+}$ \\
NAJPS & & & \\
Pre & $1.42 \pm 0.82$ & $1.67 \pm 1.36$ & -0.603 \\
Post & $0.17 \pm 0.24$ & $1.00 \pm 1.32$ & $-2.389^{+}$ \\
$\mathrm{t}$ & $6.012^{+}$ & $2.320^{+}$ & \\
Change & $-1.25 \pm 0.83$ & $-0.67 \pm 1.11$ & -1.660 \\
NPJPS & & & \\
Pre & $1.66 \pm 1.27$ & $1.53 \pm 1.33$ & 0.263 \\
Post & $0.23 \pm 0.36$ & $0.90 \pm 1.39$ & -1.798 \\
$\mathrm{t}$ & $4.500^{+}$ & $3.300^{+}$ & \\
Change & $-1.42 \pm 1.26$ & $-0.63 \pm 0.74$ & $-2.099^{+}$ \\
\hline
\end{tabular}

${ }^{*}$ Mean $\pm S D,{ }^{\dagger} p<0.05$

PAJPS: Paretic anterior joint position sense, PPJPS: Paretic posterior joint position sense, NAJPS: Non-paretic anterior joint position sense, NPJPS: Non-paretic posterior joint position sense.

Table 4. Comparison of postural alignment between the pre and posttest on each group (unit: degree)

\begin{tabular}{lccc}
\hline & $\begin{array}{c}\text { Experimental group } \\
(\mathrm{n}=16)\end{array}$ & $\begin{array}{c}\text { Control group } \\
(\mathrm{n}=15)\end{array}$ & $\mathrm{t}$ \\
\hline Neck & & & \\
Pre & $47.60 \pm 7.21^{*}$ & $49.76 \pm 6.18$ & -0.892 \\
Post & $48.38 \pm 7.32$ & $49.57 \pm 5.54$ & -0.505 \\
$\mathrm{t}$ & -0.735 & 0.120 & \\
Change & $0.78 \pm 4.24$ & $-0.20 \pm 6.30$ & 0.508 \\
Knee & & & \\
Pre & $170.86 \pm 8.25$ & $168.00 \pm 4.79$ & 1.170 \\
Post & $172.21 \pm 7.86$ & $166.00 \pm 5.73$ & $2.499^{+}$ \\
$\mathrm{t}$ & -1.533 & 1.540 & \\
Change & $1.35 \pm 3.53$ & $-2.00 \pm 5.02$ & $2.160^{+}$ \\
Ankle & & & \\
Pre & $122.31 \pm 9.27$ & $118.00 \pm 6.67$ & 1.477 \\
Post & $122.46 \pm 10.50$ & $119.50 \pm 5.06$ & 1.010 \\
$\mathrm{t}$ & -0.067 & -0.922 & \\
Change & $0.15 \pm 8.67$ & $1.50 \pm 6.28$ & -0.494 \\
\hline
\end{tabular}

${ }^{*}$ Mean $\pm S D,{ }^{+} p<0.05$.

구축이 흔히 발생하고, 이러한 이유로 과도한 요부신전과 골반의 전 방경사가 증가하여 여러가지 기능 장애 및 효율성 저하에 영향을 미 
친다. ${ }^{33,34} \mathrm{Jang}$ 등 ${ }^{21}$ 의 연구에서 뇌졸중 환자에게 서있는 자세에서 골 반경사 훈련을 실시하여 마비측 발의 접촉 양상을 개선시키고 보행 안정성을 향상시킨다고 하였고, Kim 등 35 의 연구에서 골반경사 훈련 이 마비측 다리의 안정성을 제공한다고 하였다. 본 연구에서는 경사 계를 이용한 골반경사훈련이 마비측과 비마비측 골반의 최대후방경 사에 유의한 향상이 있었고 특히, 마비측 최대후방경사에서 실험군 이 대조군에 비해 유의한 향상이 있었다. 이러한 결과는 뇌졸중 환자 에게 골반의 과도한 전방경사가 흔히 나타나지만 서있는 자세에서의 골반경사훈련을 통해 골반후방경사의 관절가동범위가 증가한 것으 로 사료된다.

고유수용성감각은 관절의 위치를 인지하여 움직임의 방향, 크기 그리고 속도를 감지하는 기능을 가지며 손상시 관절의 기능 불안, 비 정상적인 자세, 안정성의 문제를 일으킬 수 있으므로 재활의 과정에 서 고유수용성감각에 관한 훈련은 매우 중요하다. ${ }^{36} \mathrm{Kim}$ 과 Lee의 연 구에서 뇌졸중 환자에게 카메라와 모니터를 이용하여 시각적피드백 을 제공하고 골반경사훈련을 실시한 결과 보행능력이 향상되었음을 보고하였다. ${ }^{37}$ 본 연구에서는 골반경사 훈련을 실시하는 동안 치료사 가 골반의 움직임에 대한 정보와 결과에 대한 피드백을 구두로 제공 하였고, 대상자가 스스로 오차를 수정하도록 하였다. 이러한 훈련을 통하여 골반경사의 관절위치감각이 향상되었고, 대조군과 비교하여 유의한 향상을 확인하였다. $\mathrm{Bae}$ 와 $\mathrm{Oh}$ 의 연구에서 뇌졸중 환자에게 능동운동이 수동운동보다 고유수용성 위치감각 기능 향상에 도움 이 된다고 하였다. ${ }^{36}$ 본 연구에서도 골반의 능동운동을 강조하여 골 반경사의 관절위치감각 향상에 도움이 된 것으로 생각된다.

자세의 유지와 조절은 체성감각, 시각, 전정감각의 상호작용이 중 요하게 작용하는데 뇌졸중 환자는 이러한 감각들의 수집과 처리에 문제가 발생하게 되며 이로 인해 나타나는 잘못된 자세는 골반의 자 세를 비롯한 근골격계의 병리학적 문제를 야기할 수 있다. ${ }^{38}$ 본 연구 에서는 영상분석 프로그램을 사용하여 서있는 자세에서 경부, 슬관 절 그리고 발목관절의 정렬 상태를 평가하여 분석하였다. 골반경사 훈련을 통해 자세 정렬의 향상을 가져올 것이라고 가정하였으나 검 사결과 실험군과 대조군 모두 중재 전후에 유의한 차이가 없는 것으 로 나타났다. 이러한 결과는 경사계를 이용한 골반경사훈련이 근력 을 향상시키기 위한 운동보다는 골반부위의 조절에 관한 중재 방법 으로 뇌졸중 환자라는 대상자의 특성으로 인하여 선 자세에서 관절 의 정렬에 까지는 영향을 미치기 어려웠던 것으로 사료된다.

결론적으로 본 연구의 결과를 통해 만성 뇌졸중 환자에게 경사계 를 이용하여 피드백을 제공한 골반경사 훈련이 골반의 후방경사 관 절가동범위를 증가시키고, 관절위치감각을 향상시키는데 효과적이 었다는 것을 확인할 수 있었다. 따라서 임상에서 고관절 신전근의 근 력 약화 또는 굴곡근의 구축으로 인하여 골반의 전방경사가 증가되
어 있고, 고유수용성감각의 저하가 흔히 나타나는 뇌졸중 환자에게 경사계를 이용한 골반경사 훈련이 골반의 기능을 향상시키는데 도움 이 될 것이라 생각된다.

본 연구의 결과를 설명하는데 있어 몇 가지 제한점은 연구 대상자 의 수가 적어 연구 결과를 뇌졸중 환자 전체에게 확대하여 일반화하 기에는 어려움이 있고, 중재 후 초기 효과만을 보았기 때문에 중재 후 나타날 수 있는 지속 효과를 예측하기는 어렵다는 것이다. 또한, 기존 의 신경발달치료에서 골반에 관한 중재를 배제시키지 못하여 골반경 사훈련을 실험군에게만 적용하기에는 한계가 있다. 따라서 향후 많 은 대상자에게 장기 효과의 유익성을 확인하고, 골반경사훈련을 정 량화하여 적용할 수 있는 후속 연구가 필요하다고 생각된다.

\section{REFERENCES}

1. Ryerson S, Levit K. Functional movement reeducation: A contemporary model for stroke rehabilitation. Secaucus, Churchill Livingstone, 1997:15-48.

2. Wadell I, Kusoffsky A, Nilsson BY. A follow-up study of stroke patients 5-6 years after their brain infarct. Int J Rehabil Res. 1987;10:103-10.

3. Carey LM, Matyas TA, Oke LE. Sensory loss in stroke patients: Effective training of tactile and proprioceptive discrimination. Arch Phys Med Rehabil. 1993;74(6):602-11.

4. Newcomer KL, Laskowski ER, Yu B et al. Differences in repositioning error among patients with low back pain compared with control subjects. Spine. 2000;25(19):2488-93.

5. Wolpert DM, Ghahramani Z, Jordan MI. An internal model for sensorimotor integration. Science. 1995;269(5232):1880-2.

6. Miura K, Ishibashi Y, Tsuda E et al. The effect of local and general fatigue on knee proprioception. Arthroscopy. 2004;20(4):414-8.

7. Maurer C, Mergner T, Bolha B et al. Vestibular, visual, and somatosensory contributions to human control of upright stance. Neurosci Lett. 2000;281(2):99-102.

8. Friemert B, Bach C, Schwarz W et al. Benefits of active motion for joint position sense. Knee Surg Sports Traumatol Arthrosc. 2006;14(6):56470 .

9. Uchio Y, Ochi M, Fujihara A et al. Cryotherapy influences joint laxity and position sense of the healthy knee joint. Arch Phys Med Rehabil. 2003;84(1):131-5.

10. Kirker S, Simpson D, Jenner J et al. Stepping before standing: Hip muscle function in stepping and standing balance after stroke. J Neurol Neurosurg Psychiatry. 2000;68(4):458-64.

11. Yavuzer G, Eser F, Karakus D et al. The effects of balance training on gait late after stroke: A randomized controlled trial. Clin Rehabil. 2006; 20(11):960-9.

12. Vleeming A, Mooney V, Stoeckart R. Movement, stability \& lumbopelvic pain: Integration of Research and Therapy. 2nd ed. Edinburgh, Churchill Livingstone Elsevier, 2007:113-37.

13. Bae SS, Kim TY, Chung HA et al. A comprehensive kinematic approach to pelvis. J Kor Phys Ther. 1999;11(2):93-102.

14. Aruin AS. The effect of asymmetry of posture on anticipatory postural 
adjustments. Neurosci lett. 2006;401(1):150-3.

15. Carr JH, Shepherd RB, Nordholm L et al. Investigation of a new motor assessment scale for stroke patients. Phys Ther. 1985;65(2):175-80.

16. Kim JH, Chang SK. The effects of robo-horseback riding with changes of pelvic tilting and speeds on muscle activities of trunk and lower limb. J Kor Phys Ther. 2014;26(5):290-5.

17. Kong SW, Jeong YW, Kim JY. Correlation between balance and gait according to pelvic displacement in stroke patients. J Phys Ther Sci. 2015; 27(7):2171-4.

18. Wada O, Tateuchi H, Ichihashi N. The correlation between movement of the center of mass and the kinematics of the spine, pelvis, and hip joints during body rotation. Gait Posture. 2014;39(1):60-4.

19. Lennon S. Gait re-education based on the bobath concept in two patients with hemiplegia following stroke. Phys Ther. 2001;81(3):924-35.

20. Tyson SF, Selley A. The development of the stroke physiotherapy intervention recording tool (SPIRIT). Disabil Rehabil. 2004;26(20):1184-8.

21. Jang SH, Park SJ, Kim MH et al. The effect of pelvic tilt exercise with changing the body position on foot contact pattern in hemiplegic patients. J Korean soc phys med. 2010;5(3):445-53.

22. Trueblood PR, Walker JM, Perry J et al. Pelvic exercise and gait in hemiplegia. Phys Ther. 1989;69(1):18-26.

23. Davies PM. Right in the middle: Selective trunk activity in the treatment of adult hemiplegia. Berlin, Springer-Verlag, 1990:31-65.

24. Lee J. A study on the effect of pelvic tilting exercise in hemiplegic patients. Phys Ther Korea. 1998;5(2):23-38.

25. Kim JH, Hwang BY, Oh TY. Influence of trunk control using pelvic movements upon the foot pressure in patients with hemiplegia. J Kor Phys Ther. 2007;19(5):11-9.

26. Hlavacka F, Horak FB. Somatosensory influence on postural response to galvanic vestibular stimulation. Physiol Res. 2006;55(1):121-7.

27. Thikey H, Grealy M, van Wijck F et al. Augmented visual feedback of movement performance to enhance walking recovery after stroke: Study protocol for a pilot randomised controlled trial. Trials. 2012;13(1):163.

28. Comerford M, Mottram S. Kinetic control: The management of uncon- trolled movement. Amsterdam, Elsevier Churchill Livingstone, 2012:6381.

29. Molier BI, Van Asseldonk EH, Hermens HJ et al. Nature, timing, frequency and type of augmented feedback; does it influence motor relearning of the hemiparetic arm after stroke? A systematic review. Disabil and rehabil. 2010;32(22):1799-809.

30. Heino JG, Godges JJ, Carter CL. Relationship between hip extension range of motion and postural alignment. J Orthop Sports Phys Ther. 1990;12(6):243-7.

31. Nemmers TM, Miller JW, Hartman MD. Variability of the forward head posture in healthy community-dwelling older women. J Geriatr Phys Ther. 2009;32(1):10-4.

32. Raine S, Twomey LT. Head and shoulder posture variations in 160 asymptomatic women and men. Arch Phys Med Rehabil. 1997;78(11): 1215-23.

33. Fonseca S, Ocarino J, Silva P et al. Integration of stresses and their relationship to the kinetic chain. Scientific foundations and principles of practice in musculoskeletal rehabilitation. St Louis, Saunders Elsevier. 2007:476-86.

34. Park SJ. The effects of trunk and pelvic stabilization exercise using a sling on functional improvement in chronic stroke patient. Dankook University. Dissertation of Master's Degree. 2010.

35. Kim JH. An influence of trunk control using pelvic movement upon the foot pressure of patient with hemiplegia. Yong-in University. Dissertation of Master's Degree. 2007.

36. Bae EH, Oh DW. Comparison of the effects of active and passive exercises on shoulder position sense in chronic stroke patient. Journal of Special Education \& Rehabilitation Science. 201 1;50(2):167-80.

37. Kim BN, Lee WH. The influence of pelvic tilt exercise using visual feedback upon the gait charicteristics of patients with hemiplegia. J Kor Phys Ther. 2002;14(1):75-88.

38. Bonan IV, Colle FM, Guichard JP et al. Reliance on visual information after stroke. Part 1: Balance on dynamic posturography. Arch Phys Med Rehabil. 2004;85(2):268-73. 